\title{
Perancangan Sistem Informasi Akuntansi Persediaan Pabrik Beras Sukoreno Makmur Jember
}

\author{
Riski Wahyudi $^{1}{ }^{*}$, Moh.Halim² ${ }^{2}$ Rendy Mirwan Aspirandi ${ }^{3}$ \\ 1,2,3 Universitas Muhammadiyah Jember, Jawa Timur, Indonesia
}

\section{A R T I C L E I N F O}

Article history:

Received 17 August 2018

Received in revised form

20 September 2018

Accepted 18 October 2018

Available online 25

November 2018

Kata Kunci:

System informasi akuntansi

Keywords:

Accounting Information

System

\begin{abstract}
A B S T R A K
Tujuan penelitian ini adalah untuk mengetahui tentang perancangan sistem informasi akuntansi persediaan pabrik beras Sukoreno Makmur Jember. Jenis penilitian yang di lakukan adalah penelitian interpreatif dengan ilustratif case study yaitu menggambarkan sesuatu hal sehingga seseorang mampu memahaminya dan data hasil penelitian lebih berkenan dengan interpretasi terhadap data yang di temukan di lapangan. Penilitian ini menguraikan tentang sifat-sifat, karakteristik, dan keadaan yang sebenarnya dari objek penilitian yaitu dengan mengumpulkan data, mencari fakta, kemudian menjelaskan dan menganalisis data dengan cara pengumpulan data penyusustan data, selanjutnya diinterprestasikan dan di rancangkan berdasarkan landasan teori yang ada. Ada empat teknik-teknik pengumpulan data yang digunakan yaitu: Teknik wawancara, Teknik dokumentasi, Teknik Observasi, Teknik kepustakaan. Adapun informasi dalam penelitian ini di dapat dari sumber yang meliputi sebagai berikut: Staff dan karyawan bagian Produksi, Staff dan karyawan bagian Gudang, Staff dan karyawan bagian Administrasi. Berdasarkan hasil penelitian dapat diketahui bahwa Pabrik Beras Sukoreno Makmur Jember belum menerapkan Sistem Informasi akuntansi Persedian secara konseptual yang sesuai dengan Sistem Informasi Akuntansi Persedian.
\end{abstract}

\section{A B S T R A C T}

The purpose of this study is to make a financial report for the Sukoreno rice company Makmur Jember. The type of research that is carried out is interpreative research with illustrative case studies, which is something that raises someone who understands it and the research data is more pleasing to the interpretation of the data found in the field. This study describes the characteristics, characteristics, and actual conditions of the research object, namely by collecting data, looking for facts, then explaining and analyzing data by means of data collection, then interpreted and designed based on existing theories. There are four techniques from the data used, namely: interview techniques, documentation techniques, observation techniques, library techniques. Is there information in this study that can be accessed from: Production staff and staff, Warehouse staff and staff, Administration staff and staff. Based on the results of the study, it can be seen that the Sukoreno Makmur Jember Rice Plant has not yet applied the Inventory Accounting Information System in accordance with the Persedian Accounting Information System.

\footnotetext{
* Corresponding author.

E-mail addresses: riskiunmuh@gmail .com (Riski Wahyudi)
} 


\section{Pendahuluan}

Perkembangan dunia usaha saat ini mengalami persaingan yang cukup ketat, baik dalam bidang industri maupun jasa (Santi, 2010). Persaingan tersebut salah satunya disebabkan oleh kemajuan teknologi yang sangat pesat,. Oleh karena itu perusahaan terus akan dituntut untuk dapat meningkatkan seluruh aktivitasnya agar mampu bersaing dalam mempertahankan hidup suatu perusahaan, sehingga tujuan perusahaan akan tercapai (Sri, 2013).

Persediaan memegang peran penting dalam perusahaan, terutama dalam perusahaan manufaktur. Dalam perusahaan manufaktur persediaan dibagi menjadi empat jenis persediaan, yaitu persediaan bahan baku, persediaan bahan penolong,persediaan dalam proses, dan persediaan barang jadi. Dalam perusahaan dagang, persediaan hanya terdiri dari satu golongan yaitu persediaan barang dagangan yang merupakan barang yang dibeli untuk tujuan dijual kembali (Haryanto, 2015). Sedangkan pada perusahaan jasa persediaan yang di perlukan tergantung pada jasa yang dijualnya. Istilah persediaan atau (inventory) umumnya di tujukan pada barang barang yang dimiliki perusahaan untuk dijual dalam operasi bisnis normal atau dikonsumsi dalam memproduksi barang yang akan dijual (Hartanto, 2015). Deskripsi dan pengukuran persediaan biasanya membutuhkan kecermatan karena investasi dalam persediaan merupakan aktiva lancar paling besar dari perusahaan dagang. Perlu ilmu akuntansi dalam suatu perusahaan dagang. Setiawan (1994: 3), menyatakan bahwa akuntansi adalah suatu sistem informasi yang mengukur kegiatan-kegiatan bisnis dengan memproses data menjadi informasi yang berupa laporan keuangan, dan mengomunikasikan laporan keuangan tersebut kepada pihak-pihak yang memerlukan untuk pengambilan keputusan bisnis yang berkaitan dengan perusahaan tersebut. Selain itu Beliau juga menjelaskan pengertian akuntansi adalah sistem pencatatan, peringkasan, pengklasifikasian, serta pelaporan hasil-hasil keuangan yang terjadi selama suatu periode tertentu kepada pihak-pihak yang berkepentingan untuk pengambilan keputusan bisnis (Setiawan, 1994: 3). Wilkinson dalam Mulyadi, (2001:3) Menyatakan bahwa sistem merupakan suatu bentuk kerangka kerja yang terpadu yang mempunyai satu atau lebih sasaran. Persediaan merupakan barang yang diperoleh untuk dijual kembali atau bahan untk diolah menjadi barang jadi atau barang jadi yang akan dijual atau barang yang akan digunakan (Nurmailiza, 2009). Persediaan ini dapat dicatat dengan dua sistem yaitu: Sistem Periodik dan Sistem Perpetual. Persediaan adalah barang-barang yang dimiliki untuk dijual kembali atau digunakan untuk memproduksi barang-barang yang akan dijual (Zaki Baridwan, 2000:149)

Sistem Informasi Akuntansi (SIA) adalah sebuah sistem informasi yang menangani segala sesuatu yang berkenaan dengan akuntansi (Mariena, 2011). Akuntansi sendiri sebenarnya adalah sebuah sistem informasi (Rediani, 2004). Faktor-faktor yang dipertimbangkan dalam penyusunan sistem informasi akuntansi: Sistem informasi akuntansi yang disusun harus memenuhi prinsip (1) cepat yaitu sistem informasi akuntansi harus menyediakan informasi yang diperlukan dengan cepat dan tepat waktu serta dapat memenuhi kebutuhan dan kualitas yang sesuai, (2) aman yaitu sistem informasi harus dapat membantu menjaga keamanan harta milik perusahan. (3) murah yang berarti bahwa biaya untuk menyelenggarakan sistem informasi akuntansi tersebut harus dapat ditekan sehingga relatif tidak mahal (Daud,2014).

Kabupaten Jember merupakan kawasan yang dijadikan sebagai sentra beras di Jawa Timur, karena produksi padi di Jember pada tahun 2013 mencapai 930.027 ton dan tahun 2014 mencapai 1.023 .567 ton (Badan Pusat Statistik, 2014). Sedangkan jumlah penduduk Kabupaten Jember 2013 sebanyak 2.381.400 jiwa dan pada tahun 2014 mencapai 2.394.608 jiwa (Badan Pusat Statistik, 2017). PB.Sukoreno merupakan salah satu perusahaan penghasil beras terbaik di daerah Jember bagian utara yang kualitasnya sangat baik. Perusahaan yang berdiri sejak tahun 1986 ini menghasilkan kualitas beras yang baik dan permintaan pasar akan produk beras pada perusahaan ini semakin tahun semakin meningkat.

\section{Metode}

Jenis penilitian yang di lakukan adalah penelitian interpreatif dengan ilustratif case study yaitu menggambarkan sesuatu hal sehingga seseorang mampu memahaminya dan data hasil penelitian lebih berkenan dengan interpretasi terhadap data yang di temukan di lapangan. Penilitian ini menguraikan tentang sifat-sifat, karakteristik, dan keadaan yang sebenarnya dari objek penilitian yaitu dengan mengumpulkan data, mencari fakta, kemudian menjelaskan dan menganalisis data dengan cara pengumpulan data penyusustan data, selanjutnya diinterprestasikan dan di rancangkan berdasarkan landasan teori yang ada.

Adapun jenis-jenis data yang telah dikumpulkan oleh penulis adalah sebagai berikut: 1) Data primer, merupakan sumber data penelitian yang diperoleh secara langsung dari sumber aslinya yang berupa wawancara, jajak pendapat dari individu atau kelompok (orang) maupun hasil observasi dari 
suatu obyek, 2) Data Sekunder, merupakan sumber data penelitian yang diperoleh melalui media perantara atau secara tidak langsung yang berupa buku, catatan, bukti yang telah ada, dokumen, laporan historis atau arsip baik yang dipublikasikan maupun yang tidak dipublikasikan secara umum. Ada empat teknik-teknik pengumpulan data yang digunakan oleh penulis yaitu: Teknik wawancara, Teknik dokumentasi, Teknik Observasi, Teknik kepustakaan. Adapun informasi dalam penelitian ini di dapat dari sumber yang meliputi sebagai berikut: Staff dan karyawan bagian Produksi, Staff dan karyawan bagian Gudang, Staff dan karyawan bagian Administrasi.

\section{Hasil dan pembahasan}

Pabrik Beras Sukoreno Makmur merupakan salah satu perusahaan yang berada di daerah Kabupaten Jember, tepatnya terletak di Dusun Grugul RT.03 RW.03 Sukoreno, Kecamatan Kalisat. Pabrik Beras Sukoreno Makmur berdiri pada tanggal 20 Juni 1986 oleh Bapak H. Abdurrahman sebagai perintis Usaha Dagang (UD) Penggilingan Padi Sukoreno Makmur. Pada awalnya, Pabrik Beras Sukoreno Makmur membuka usaha kecil-kecilan untuk mengakomodir untuk kepentingan masyarakat yang mebutuhkan teknik pengolahan padi menjadi beras. Pada saat itu masyarakat menjual padinya pada PB. Penggilingan Padi, selanjutnya akan dikemas dan didistribusikan di wilayah Jember dan sekitarnya.

Usaha dasar Penggilingan Padi Sukoreno mengalami perkembangan yang cukup signifikan, sehingga pihak pemilik memandang perlunya untuk mengembangkan usaha. Maka dari itu pada tahun 1993 UD. Penggilingan Padi Sukoreno Makmur memiliki ijin dari pemerintah berupa SIUP nomor 12327/13-8/PM/V/93, dan berubah menjadi Pabrik Beras Sukoreno Makmur dengan produk bernama Cap Lonceng. Saat ini pimpinan telah diganti oleh Bapak H. Roni yang tidak lain adalah Putra dari Bapak H. Abdurrahman. Faktor-faktor produksi mengalami perombakan untuk mendukung strategi perusahaan jangka panjang dan juga untuk menjaga eksistensi perusahaan dengan pesaing. Faktor-faktor produksi yang paling penting diperbaiki dalam perusahaan, yaitu mesin-mesin produksi yang menjadi faktor pendukung kegiatan perusahaan. Saat ini perusahaan telah memiliki satu mesin penggerak, satu mesin giling yang terdiri dari tiga mesin pemecah kulit, dan dua mesin pemoles.

\section{Struktur Organisasi}

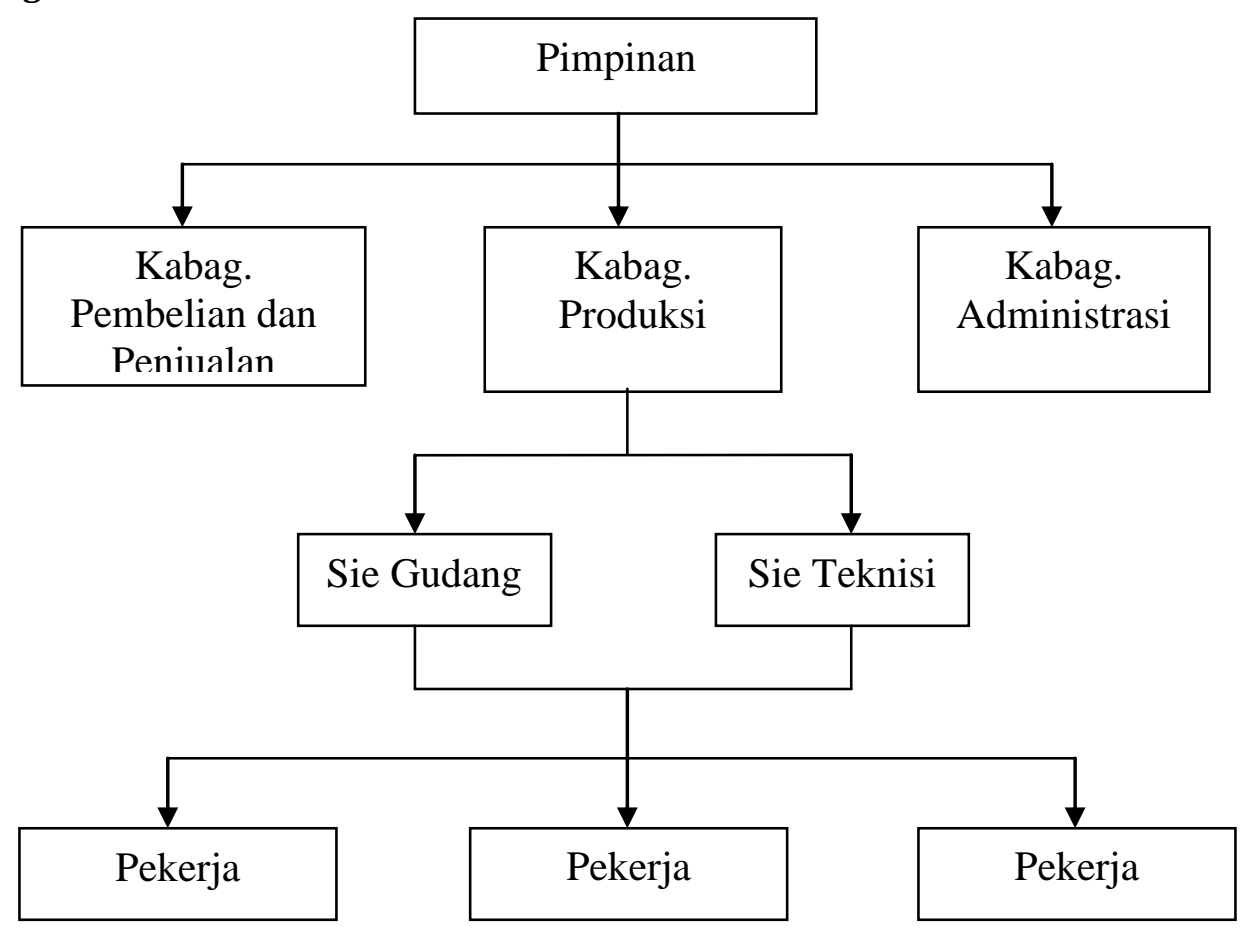

Sumber : PB. Sukoreno Makmur

Gambar 1. Struktur organisasi Pabrik Beras Sukoreno Makmur

\section{Prosedur Pengelolaan Persediaan}

Pabrik Beras melaksanakan pengelolaan persediaan barang dagangan sebagai berikut:

1). Prosedur Permintaan Pembelian Barang Dagangan

a. Prosedur ini di mulai dari bagian yang membutuhkan barang, dalam hal ini adalah bagian gudang. Bagian ini memeriksa barang apa saja yang akan di lakukan pemesanan barang kembali berdasarkan 
pertimbangan tertentu misalnya perputaran persediaan jumlah persediaan minimum yang ada di gudang. Berdasarkan bantuan yang dapat di lihat pada kartu persediaan barang dagangan yang ada di gudang, sehingga bagian gudang bisa menganalisis barang apa saja yang perlu di lakukan pemesanan barang kembali. Selanjutnya pelaksana gudang mmbuat estimasi order jumlah barang yang di minta, dan harga.

b. Pembelian atau pembuatan pesanan pembelian hanya di lakukan berdasarkan estimasi order pembelian yang ditandatangani oleh bagian gudang dan pimpinan sebagai persetujuan bahwa barang tersebut benar-benar di butuhkan kemudian di serahkan kepada bagian keuagan. c.Bagian keuangan menetapkan jadwal pemesanan kepada Supplier.

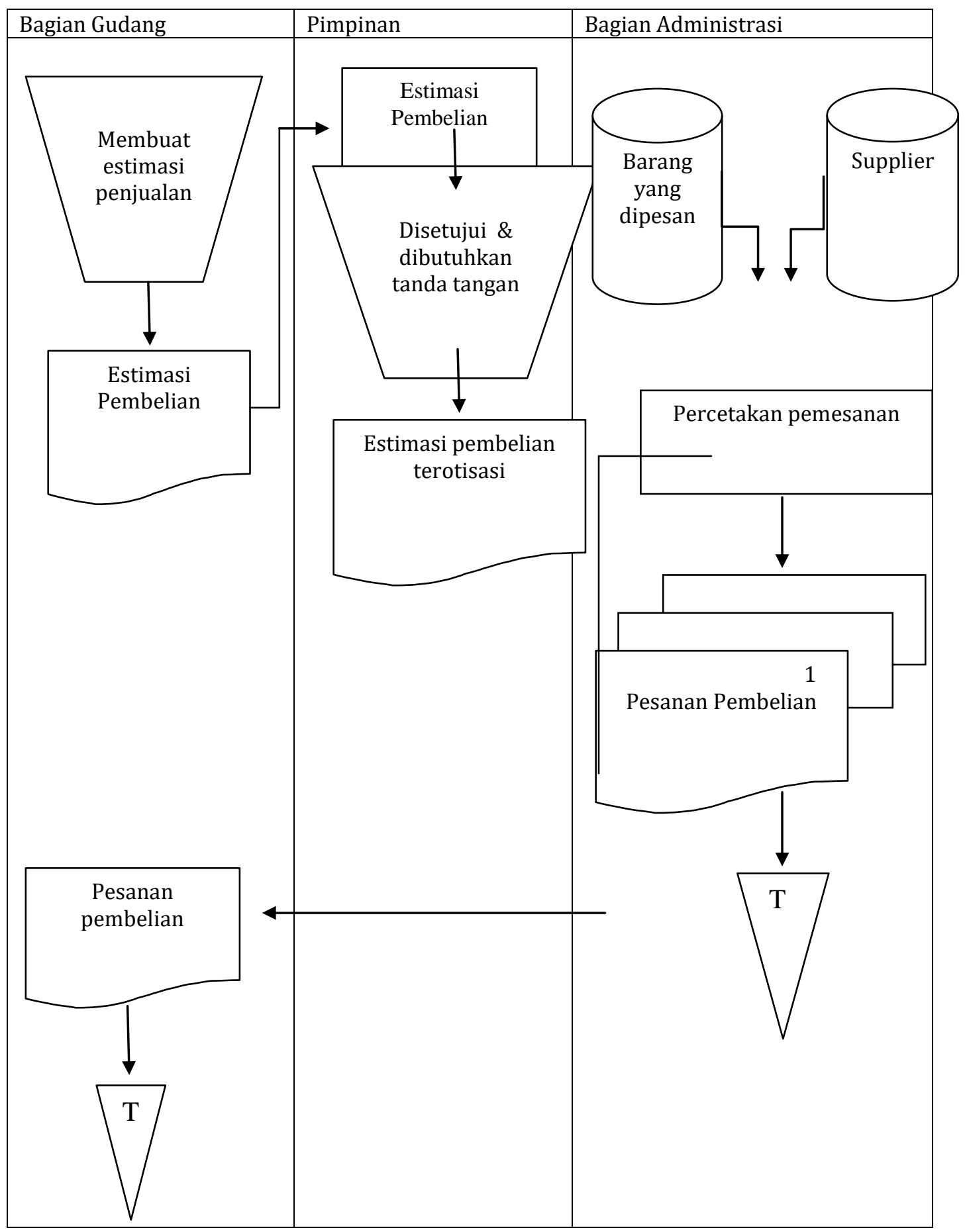

Sumber data : PB.Sukoreno Makmur Jember

Gambar 2. Prosedur Pengelolaan 
Bagan Alir Permintaan Pembelian Barang Dagangan

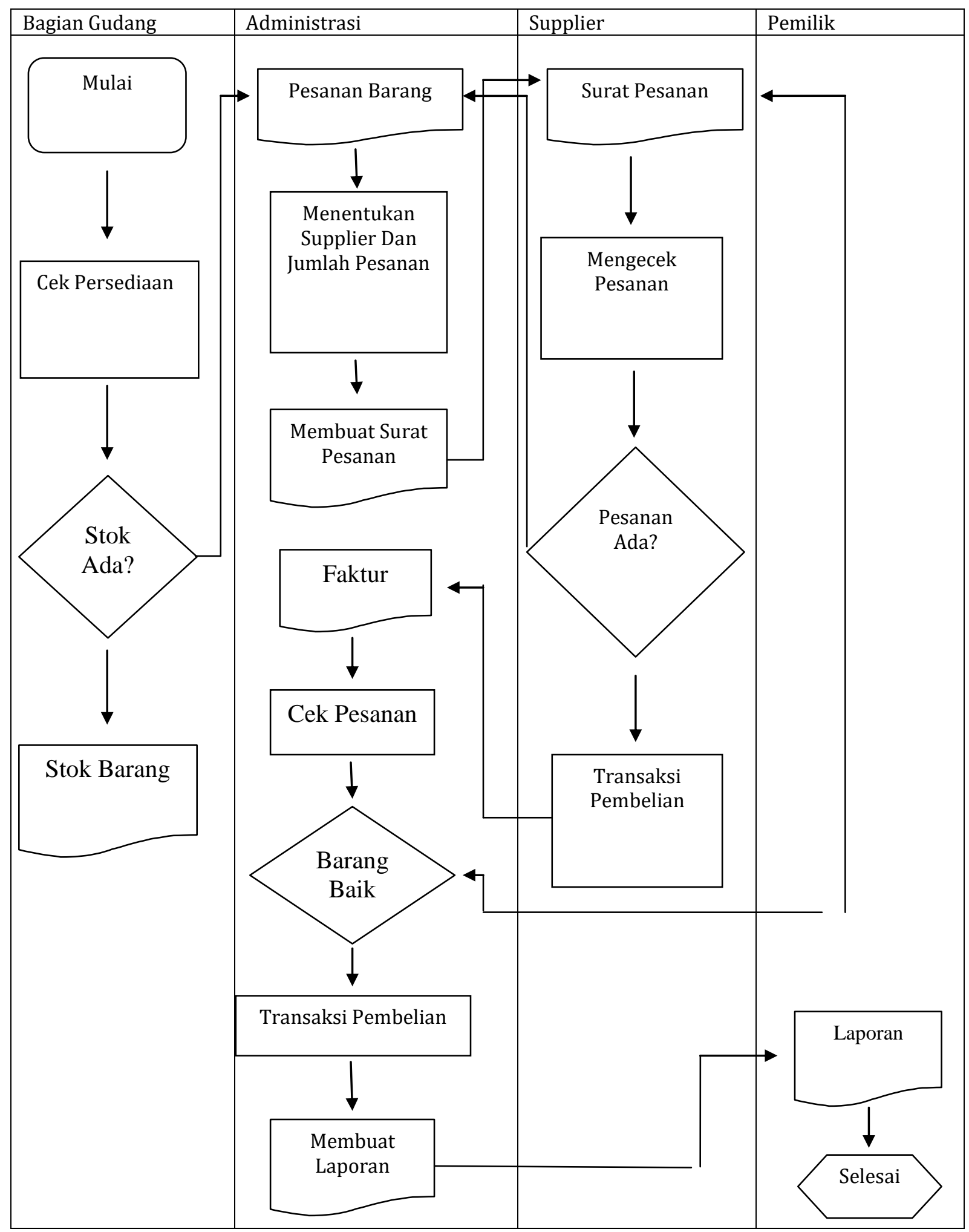

Gambar 3. SIA Persediaan Barang Dagangan Secara Konseptual (Flowchart) 


\section{Simpulan dan saran}

Dari hasil penelitian tentang Sistem Informasi Akuntansi barang dagangan, yang ada di PB.Sukoreno maka penulis menyimpulkan sebagai berikut : 1) Sistem informasi akuntansi yang di terapkan dalam persedian barang dagangan di PB. Sukoreno Makmur sudah memadai karena di dalam pabrik tersebut sudah memenui unsur-unsur sistem informasi akuntansi, yaitu sumber daya manusia (SDM), peralatan ( Komputer, kalkulator, dan printer ), catatan ( Jurnal, buku besar, dan laporan ). Dari semua unsur-unsur sudah di jelaskan maka sudah dapat menghasilkan informasi yang berguna bagi pemilik pabrik untuk mengurangi resiko pada persediaan barang dagangan dalam mencapai tujuan yang baik bagi perusahaan/pabrik. 2) Lingkungan di pabrik di nilai sudah sangat baik karena sudah di lakukan sebagai mana mestinya yaitu adanya integritas dan nilai etika, komitmen terhadap kompetensi, struktur organisasi, kebijakan sumber daya manusia. Akan tetapi pabrik beras sukoreno belum mempunyai komite audit di karenakan belum memiliki auditir yang berfungsi untuk secara khusus melakukan pemeriksaan dalam prosedur dan pencatatan dalam perusahaan/pabrik. 3) Penilaian resiko yang di terapkan di PB. Sukoreno Makmur atas persediaan barang dagangan sudah cukup baik karena pabrik sudah menerapkan kebijakan stock opname secara rutin dan konsisten untuk megatasi resiko tersebut.

\section{Daftar Rujukan}

Baridwan,Zaki. 2000. “Intermediate Accounting”. Edisi kedelapan Yogyakarta :BPFE Yogyakarta.

Daud, Rochmawati. 2014."Pengembangan Sistem Informasi Akuntansi Penjualan Dan Penerimaan Kas Berbasis Komputer Pada Perusahaan Kecil (Studi Kasus Pada Pt. Trust Technology). Jurnal Manajemen Dan Bisnis Sriwijaya Vol.12 No.1 Maret 2014

Handoko,T.H. 1991. “Dasar-Dasar Manajemen Produksi dan Operasi”. Jakarta: BPFE Yogyakarta.

Hertanto Adi Hermawan. 2015 “ Sistem Informasi Akuntansi Persediaan Barang Dagang Pada UMKM Treant Skateshop Semarang”.

Heryanto Adi Hermawan Haryanto. 2015 “Jurnal Sistem Informasi Akuntansi Persedian Barang Dagang Pada UMKM Treant Skateshop Semarang”.

Mariena, Sukmawati dan Hanura Ian. 2011 "Sistem Informasi Akuntansi Penjualan pada PT (Studi Kasus Pada PT.Afixkogyo Indonesia) Jurnal PA Sistem Informasi Akuntansi Penjualan, Bandung.

Mulyadi. 2001 “Sistem Akuntansi.” Edisi ketiga. Jakarta: Salemba Empat,

Nurmailiza, Tengku. 2009. "Analisis Pengendalian Intern Atas Persediaan Barang Dagangan pada PT. Sabda Cipta Jaya." Skripsi. Medan: Universitas Sumatra Utara.

Radiani, Dian. 2004 “ Peranan Pengendalian Intern Persedian Barang Dagangan Dalam Menunjang Efektivitas Pengelolaan Persediaan Barang Dagangan ( studi kasus pada toserba Yogya Garut ). Skripsi, Program Sarjana Universitas Widyatama.

Setiawan, Chandra. 1994. "Pengantar Akuntansi 1".Yogyakarta : Bagian Penerbitan Sekolah Tinggi Ilmu Ekonomi YKPN Yogyakarta.

Shanty. 2010 “Analisis Aktivitas Pengendalian Intern Pada PT. Cemara Cahaya Gemlang. Jurnal Akuntansi, Universitas Diponegoro Semarang.

Sri Luayyi. 2013“Evaluasi Sistem pengendalian Intern Persediaan Bahan Baku Untuk Memperlancar Proses Produksi ( Studi Kasus Pada PR. KN Jaya Sentosa Kediri)”.

Widjayanto, Nugroho. 2004. “Sistem Informasi Akuntansi”. 